Puede citar este artículo como:

Lafuente Gómez, Mario. «Pragmatismo y distinción: el estatus privilegiado de la ciudad de Zaragoza en la baja edad media». Anales de la Universidad de Alicante. Historia Medieval, N. 19 (2015-2016): 221-240, DOI:10.14198/medieval.2015-2016.19.08

\title{
PRAGMATISMO Y DISTINCIÓN: EL ESTATUS PRIVILEGIADO DE LA CIUDAD DE ZARAGOZA EN LA BAJA EDAD MEDIA
}

\author{
Mario Lafuente Gómez* \\ Universidad de Zaragoza
}

\section{RESUMEN}

Este artículo analiza la evolución del estatus privilegiado de la ciudad de Zaragoza entre el reinado de Jaime II (1291-1327) y el de Fernando II (14791516). Para ello, se han observado tres de sus expresiones más directas: la vigencia de los estatutos otorgados a la ciudad en su etapa fundacional (Fuero de los infanzones de Aragón y Privilegio de los Veinte), la obtención de nuevos privilegios de inmunidad fiscal y la configuración de una categoría social a medida de la oligarquía urbana. La conservación de ese estatus exigió de una labor de actualización permanente, en la que tomaron parte tanto la monarquía como las autoridades locales.

Facultad de Filosofía y Letras, Departamento de Historia Medieval, C/ Pedro Cerbuna, 12, 50009, Zaragoza. Dirección de correo electrónico: mariolg@unizar.es. Un adelanto de este artículo, con el título «Identidad urbana y distinción social: la ciudad de Zaragoza y la monarquía aragonesa en los siglos XIV y XV», fue presentado en el seminario Franquezas y privilegios: evolución de una política de la merced en la Península Ibérica y las Indias, siglos XIV-XVI, que se celebró en la Universidad de Córdoba los días 19 y 20 de diciembre de 2013, con la coordinación del Dr. Luis Salas Almela. Asimismo, el trabajo forma parte de la actividad científica desarrollada en el marco del Grupo Consolidado CEMA (Universidad de Zaragoza), dirigido por J. Ángel Sesma y financiado por el Gobierno de Aragón y el Fondo Social Europeo (cema.unizar.es); y de los Proyectos de Investigación HAR2012-32931 (I+D+i, Ministerio de Economía y Competitividad), cuyo investigador principal es Carlos Laliena, y JIUZ-2012-HUM02 (Universidad de Zaragoza), que dirige Concepción Villanueva. Siglas y abreviaturas utilizadas: ACA, Archivo de la Corona de Aragón; AMZ, Archivo Municipal de Zaragoza. 
Palabras clave: Zaragoza, Baja Edad Media, Ciudadanía, Monarquía, Fiscalidad.

\begin{abstract}
This article analyzes the development of the privileged status of Saragossa, the main city of the Kingdom of Aragon, between the reigns of Jaime II (1291-1327) and Fernando II (1479-1516). In order to do it, three items have been observed: the applicability of the two great privileges the city got after the feudal conquest (Fuero de los infanzones de Aragón and Privilegio de los Veinte); the meaning of the new privileges added in the 14th and 15th Centuries; and the the configuration of a new social group by the urban oligarchy. The Aragonese monarchy and the members of the city council took part in this historical process and shared in its benefits.
\end{abstract}

Keywords: Saragossa, Late Middle Ages, Citizenship, Monarchy, Tax System.

“...la çiudat de Çaragoça, la qual es a nos muy cara, como aquella que es cabeça del nuestro regno d'Aragon e muy noble entre las otras ciudades de nuestra senyoria..."

Pedro IV de Aragón, 1363

\title{
INTRODUCCIÓN: UNA GRAN CAPITAL PARA UN REINO EN EXPANSIÓN
}

Desde el momento de su incorporación al reino de Aragón, en diciembre de 1118, la ciudad de Zaragoza fue dotada por la monarquía aragonesa de una personalidad jurídica particular y, sobre todo, de un estatus de superioridad que aspiraba a suceder, en el contexto del nuevo Estado feudal, las dignidades propias tanto de la rememorada Caesaraugusta romana como de la ambicionada Saraqusta islámica. Para los artífices de la conquista, comenzando por el propio monarca, Alfonso I (1104-1134), el dominio sobre la gran capital del valle del Ebro se había planteado, desde finales del siglo $\mathrm{XI}$, como un objetivo sublime -como una cruzada, de hecho, a partir del concilio de Toulouse de 1117-, cuya consecución significaba no sólo una demostración de fuerza o un ejercicio de ostentación, sino que además su-

1 Fragmento de la carta de nombramiento de don Pedro, conde de Urgell y vizconde de Ager, como capitán de la ciudad de Zaragoza. ACA, Cancillería, registro 1385, f. 98r (1363, marzo, 6. Monzón). 
ponía un auténtico ritual de paso en la carrera ascendente de la dinastía y la aristocracia aragonesas. Así, una vez consumada la capitulación almorávide y prácticamente en cuestión de meses, el epicentro de la autoridad política y espiritual del reino de Aragón se trasladó, para quedarse, hasta las orillas del Ebro, convirtiéndose inmediatamente la ciudad de Zaragoza en el gran icono del poder real'2.

La relación establecida a partir de entonces entre la monarquía y la gran urbe del reino o, más concretamente, entre los sucesivos reyes y reinas de Aragón, y los grupos sociales afincados en Zaragoza, estuvo fuertemente influenciada por la solemnidad del momento fundacional y el prestigio irradiado entonces por la propia ciudad. En términos estrictamente jurídicos, la categoría de la nueva capital se había plasmado entonces en la concesión a sus pobladores, por parte de Alfonso I, de dos códigos extraordinariamente generosos y excepcionales en el contexto de las villas y ciudades aragonesas. El primero de ellos, en orden cronológico, es el denominado Fuero de los infanzones de Aragón, código que equiparaba el estatus de los zaragozanos con el de la pequeña nobleza del reino y que la ciudad recibió en enero de $1119^{3}$. Esta identificación sirvió, ante todo, para marcar una clara línea divisoria entre aquellos y la población adscrita al régimen de servidumbre, división que debía materializarse, entre otros aspectos, en la exención del pago de censos, la sujeción a prácticas honorables en los procedimientos judiciales y en la observancia de todo un conjunto de usos de tipo ritual y simbólico 4 . Pero, además, este instrumento tenía como finalidad distinguir a las personas arraigadas en Zaragoza del resto de la población urbana aragonesa, que, a comienzos del siglo XII, comenzaba ya a disfrutar de no pocos privilegios específicos, reflejados en los fueros locales y expresados, normalmente, en términos de inmunidad fiscal ${ }^{5}$.

2 LACARRA DE MIGUEL, J.M., «La conquista de Zaragoza por Alfonso I (18 diciembre 1118)», Estudios dedicados a Aragón de José María Lacarra, Universidad de Zaragoza, Zaragoza, 1987, pp. 79-112. Sobre el significado de la anexión de Zaragoza en el contexto de la expansión feudal aragonesa, véase LALIENA CORBERA, C., «Expansión territorial, ruptura social y desarrollo de la sociedad feudal en el valle del Ebro, 10801120», De Toledo a Huesca. Sociedades medievales en transición a finales del siglo XI (10801100), eds. C. Laliena Corbera y J.F. Utrilla Utrilla, Zaragoza, 1998, pp. 199-227.

3 Publica CANELLAS, A., Colección Diplomática del Concejo de Zaragoza, Ayuntamiento de Zaragoza, Zaragoza, 1972, t. I, doc. 1, pp. 83-84.

4 LALIENA CORBERA, C., Siervos medievales de Aragón y Navarra en los siglos XI-XIII, Prensas de la Universidad de Zaragoza, Zaragoza, 2012, pp. 477-479.

5 Algunos de esos fueros son los de Alquézar (1069), Jaca (1077), Barbastro y Huesca (1100), y Ejea (1105). LALIENA CORBERA, C., «La sociedad aragonesa en la época de Sancho Ramírez (1050-1100)», Sancho Ramírez, rey de Aragón, y su tiempo, 1064-1094, coord. E. Sarasa Sánchez, Instituto de Estudios Altoaragoneses, Huesca, 1994, pp. 65-80. 
El segundo código, otorgado tan sólo diez años más tarde, es el llamado Privilegio de los Veinte, mediante el cual se aseguraban a la población de la capital aragonesa tres tipos de beneficios: la libre explotación de gran cantidad de recursos naturales en todo el reino, la exención del pago de diversos derechos de tránsito de mercancías y la posibilidad de resolver, de manera autónoma, una gran variedad de conflictos y procedimientos judiciales, permitiendo incluso la intervención militar del concejo sin mediación del rey, si se consideraba que el agravio sufrido por la ciudad o por cualquiera de sus vecinos había sido evidente ${ }^{6}$. Dentro de nuestra argumentación, interesan especialmente las dos primeras prescripciones citadas, ya que afectan directamente a dos de las actividades económicas más extendidas entre la oligarquía local durante toda la Edad Media, concretamente la ganadería y el comercio. En efecto, el enunciado de este privilegio recoge la libre explotación de todos los pastos del sector del valle del Ebro sometido, a la altura de 1129, al dominio de Alfonso I, es decir, desde Novillas, primera localidad aragonesa en ser atravesada por el río, hasta Pina de Ebro, ya que el territorio situado más allá de esta última población se encontraba en la órbita de las ciudades musulmanas de Lérida y Tortosa, controladas todavía por el poder almorávide ${ }^{7}$. Por otra parte, la exención del pago de derechos de tránsito (lezdas) se extendía, en principio, sobre todas las tierras dependientes de la monarquía, salvo en ciertos puertos, que no fueron

6 Publica CANellas, A., Colección Diplomática, cit., t. I, doc. 5, pp. 87-89. La particular denominación con la que es conocido este código procede de la fórmula enunciada por el monarca, Alfonso I, para sancionar su expedición, según la cual los destinatarios del mismo, es decir, los pobladores (populatores) de Zaragoza, debían designar entre ellos a veinte hombres que juraran el cumplimiento de su contenido y, a su vez, hicieran jurar, posteriormente, al resto. Véase al respecto AGUDO ROMEO, M. ${ }^{a}$ M., «No os dejéis hacer fuerza por ningún hombre. El privilegio de los Veinte de la ciudad de Zaragoza, un documento medieval ejemplar», El Municipio en Aragón, Diputación Provincial de Zaragoza, Zaragoza, 2004, pp. 8797; y, de la misma autora, "Una concesión de Alfonso I el Batallador a Tudela: el denominado privilegio de los Veinte y los fueros de Zaragoza», Navarra: memoria e imagen, VI Congreso de Historia de Navarra, Gobierno de Navarra, Pamplona, 2006, pp. 95-108.

7 «In primis persolto vobis totos illos sotos de Novellas in iuso usque ad Pinam, quod talietis ibi ligna sicca et tamarizas et tota alia ligna, extra salices et extra alias arbores grandes que sunt vetatas. Et similiter persolto vobis illas herbas totas de illos sotos, ubi pascant vestras bestias, et de totos alios terminos ubi alias bestias pascunt. Et persolto vobis totas illas aquas quod pesquetis ubi potueritis, sed totos illos solgos qui fuerint ibi prensos sedeant meos, et prendat eos meo merino per ad me. Adhuc etiam persolto vobis totos illos alios montes quod talietis ligna et faciatis carbonem. Et absolto vobis illas petras et illo gisso quod prendatis et faciatis ubi melius potueritis.» CANELlAS, A., Colección Diplomática, cit., t. I, pp. 87-88. 
nombrados en el documento pero que, probablemente, se localizaban en la frontera con el reino de Francia ${ }^{8}$.

El sentido histórico de los dos códigos señalados debe ser interpretado en el contexto de la organización política del Estado feudal, en los albores del siglo XII, y, muy particularmente, desde la óptica de una monarquía fuertemente necesitada de un espacio, tanto físico como simbólico, desde el que proyectar un poder y una autoridad en expansión. Colmar esta necesidad exigía asegurar, primero, el poblamiento de la gran ciudad pero, además, obligaba a señalar específicamente la distinguida condición de sus pobladores, a través de las fórmulas que el utillaje mental reservaba para ello, esto es, la asimilación entre la condición infanzona y la de aquellas personas que acudiesen a poblar la ciudad de Zaragoza. La envergadura del objetivo anhelado por la monarquía explica, pues, la amplitud de los privilegios otorgados entonces y los justifica, dada la enorme rentabilidad que, al menos en el campo de lo simbólico, el dominio sobre Zaragoza podía proporcionar a la dinastía aragonesa.

La configuración de la Zaragoza cristiana en las primeras décadas de su adscripción al reino aragonés permite definirla, pues, como una ciudad privilegiada, en el sentido más literal de la expresión, ya que la autoridad emisora de los privilegios actuó, al otorgarlos, sin exigir contraprestaciones de ninguna persona ni entidad de ningún tipo. Sin embargo, una vez superada la fase de instalación del nuevo poder feudal en la ciudad y, sobre todo, después de haber sido asegurado el dominio del Valle del Ebro y de la Extremadura aragonesa por la monarquía, durante el principado de Ramón Berenguer IV (1137-1164) y el reinado de Alfonso II (1164-1196), los privilegios obtenidos por la capital pasaron a inscribirse en una dinámica de negociación y pacto desarrollada entre dos partes: de un lado, la monarquía, que actuó para solicitar y recibir todo tipo de servicios, comprometiéndose implícitamente a ofrecer y compensar a sus interlocutores; y, de otro lado, los sucesivos gobiernos urbanos, sometidos al hábito de responder positivamente a la corona, aunque cada vez mejor posicionados para exigir todo tipo de contraprestaciones y beneficios.

Pero, ni la generosidad del poder real, en los inicios, ni la posterior adopción de un sistema de negociación y pacto para confirmar o renovar la condición estatutaria de la ciudad constituyen, en sí, rasgos singulares de la ciudad

8 «Adhuc enim mando vobis quod non donetis lezdas in tota mea terra nisi ad illos portos, sicut iam ante fuit prisum et taliatum inter me et vos, pro tali conditione: quod vos similiter guardetis meas lezdas et meas monetas et totas meas redditas sicut melius potueritis ad meam fidelitatem.» Ibídem, p. 88. 
de Zaragoza. De hecho, se trata de dos fenómenos que se insertan en la dinámica del cambio institucional experimentado por los estados feudales europeos en los siglos XII y XIII, un cambio que Thomas Bisson ha definido en términos de crisis y que Carlos Laliena, para el caso particular del reino de Aragón, ha nombrado como la metamorfosis del Estado feudal ${ }^{9}$. El elemento que caracterizó la trayectoria histórica de la capital aragonesa, dentro de este proceso histórico, fue la capacidad de la oligarquía urbana para actualizar, prácticamente a cada generación, el espíritu y la operatividad de los dos grandes privilegios emitidos por Alfonso I. En efecto, tanto el Fuero de los infanzones de Aragón como el Privilegio de los Veinte no sólo mantuvieron su vigencia, al ser confirmados por cada uno de los sucesivos reyes de Aragón, sino que se convirtieron, al menos hasta el reinado de Fernando II (1479-1516), en dos instrumentos perfectamente operativos a la hora de distinguir a los vecinos y ciudadanos de Zaragoza del resto de la población urbana aragonesa.

En los tres apartados siguientes, intentaremos explicar la actuación de la oligarquía zaragozana para adaptar el sentido de los aquellos privilegios durante la Baja Edad Media, teniendo en cuenta que la aplicación de su contenido, en la práctica, exigía de una labor casi permenente de negociación y se desarrollaba, con frecuencia, en medio de conflictos que enfrentaban a la corporación municipal con otros concejos o incluso con la propia monarquía. Para ello, analizaremos, en primer lugar, el alcance real de la exención de derechos de pasto y de tránsito, los matices que aquella fue acumulando a lo largo del tiempo y, sobre todo, el éxito de la oligarquía zaragozana a la hora de resolver, en su propio beneficio, los numerosos pleitos originados en relación con su cumplimiento. Este aspecto refleja bien, en nuestra opinión, cómo el mantenimiento de la condición privilegiada expresada en los instrumentos normativos participa, necesariamente, de un juego de fuerzas en el que es preciso desenvolverse con autoridad. A continuación, nos preguntaremos por el modo en que los privilegios instituidos fueron ampliados $-\mathrm{o}$, desde el punto de vista de la ciudad, mejorados-, deteniéndonos para ello en algunos de los contextos históricos que ofrecieron oportunidades en este sentido. Como veremos, dichas oportunidades se presentaron, especialmente, a raíz de la solicitud de servicios económicos por la monarquía y, en su desarrollo, los representantes del concejo apuntaron sistemáticamente hacia el perfeccio-

9 BISSON, Thomas N., La crisis del siglo XII. El poder, la nobleza y los orígenes de la gobernación europea, Crítica, Barcelona, 2010 (ed. or. 2009); LALIENA CORBERA, C., «La metamorfosis del Estado feudal. Las estructuras institucionales de la Corona de Aragón en el periodo de expansión (1208-1283)», La Corona de Aragón en el centro de su Historia. 1208-1458. La monarquía aragonesa y los reinos de la Corona, Gobierno de Aragón, Zaragoza, 2009, pp. 67-98. 
namiento de la inmunidad fiscal. Por último, veremos cómo este proceso de sofisticación institucional implicó, también, la sanción jurídica de un fenómeno de diferenciación social en el seno del grupo dirigente de la ciudad, con la configuración de la categoría de ciudadanos honrados y su plena identificación con la nobleza, a través del libre acceso al estatus de la caballería.

\section{LA REPRODUCCIÓN DEL ESTATUS PRIVILEGIADO: UNA LABOR PERMANENTE}

La actuación de la oligarquía zaragozana para hacer valer el sentido de los dos privilegios originales en sucesivos contextos y coyunturas, obteniendo, además, un éxito notable en casi todos ellos denota una gran capacidad y fortaleza negociadoras por parte del poder urbano, pero, también, un interés secular por parte de la monarquía por mantener y, ocasionalmente, aumentar, el estatus distintivo de la población zaragozana. La importancia de este hecho es fundamental si tenemos en cuenta que, en las primeras décadas del siglo XII, los documentos propios de la legislación local presentaban todavía una notable ambigüedad en sus fórmulas, por lo que su aplicación, lejos de ser unívoca, quedaba necesariamente sujeta a factores externos al texto escrito, muy relacionados con prácticas consuetudinarias y con la autoridad reconocida mutuamente por las partes afectadas.

Dicho de otro modo: el sentido último de la ley escrita dependía generalmente de la autoridad y la influencia que los afectados eran capaces de ejercer sobre el otro o de reconocerse entre sí, y, dentro de este juego, conviene señalar que tanto la monarquía como los agentes del poder urbano tuvieron muy presente, durante toda la baja Edad Media, el espíritu de los privilegios otorgados por Alfonso I. Los ejemplos más significativos de este hecho vienen representados por las múltiples oportunidades que se presentaron, durante toda la Edad Media, para clarificar los beneficios que debían disfrutar los vecinos de Zaragoza respecto a la explotación de pastos y a la exención del pago de derechos de tránsito, es decir, lezdas y peajes. Según el citado Privilegio de los Veinte, de 1129, los zaragozanos podían apacentar sus ganados libremente en todas las dehesas del Valle del Ebro, quedando además exentos del pago de derechos de tránsito en todos los dominios de la monarquía -algo previsto también en el Fuero de los infanzones de Aragón-, con algunas excepciones acordadas de forma oral y que ni siquiera fueron puestas por escrito. Con tan precarias referencias, no es extraño que, después de la expansión de los dominios de la monarquía aragonesa en los siglos XII y XIII, proliferasen los problemas relacionados con el ámbito de aplicación de los privilegios otorgados a los zaragozanos. 
El desarrollo y la resolución de estos coflictos sentó jurisprudencia y fue concretando, paulatinamente, la ambigüedad característica de la fase más antigua. El reinado de Jaime II (1291-1327) supuso un momento clave dentro de este proceso, ya que algunas de las disputas más graves, entre las relacionados con pastos y peajes, se produjeron, precisamente, en este periodo. Así, a finales de 1300, Jaime II tuvo que recordar, por escrito, la libertad de pasto para las cabañas ganaderas de los vecinos de Zaragoza, con las únicas excepciones de dos dehesas reales situadas cerca de la ciudad, aguas abajo del Ebro, en la localidad de Pina ${ }^{10}$. El documento resultante de la intervención real fue ampliamente difundido por los oficiales del consistorio zaragozano, a juzgar por la frecuencia con la que aparece trasladado entre los pergaminos del Archivo Municipal. Concretamente, de los poco más de cien documentos conservados para la primera mitad del siglo XIV, siete incluyen copia de este privilegio $^{11}$. La multiplicación de testimonios de este tipo indica que, a pesar de todo, tanto los oficiales reales como los arrendadores de este tipo de derechos solían ignorar, deliberadamente, este tipo de privilegios, dando lugar a pleitos que, excepcionalmente, podían resolverse también en contra de los intereses de la capital. Así, por ejemplo, en 1326, sabemos que en el término de la ciudad de Albarracín se cobraba a los zaragozanos cinco carneros por cabaña en concepto de derechos de pasto ${ }^{12}$.

Por otro lado, la imprecisión relativa al pago de derechos de tránsito experimentó una profunda revisión, también, en el año 1300, cuando, poco después de haber ratificado la libertad de pasto para las cabañas zaragozanas, Jaime II determinó la exención general de lezdas y peajes en beneficio de los

10 «Cum per privilegia nostrorum antecessorum et per nos confirmata fidelibus nostris civibus Cesarauguste et eorum successoribus, data eisdem fuerit et concessa omnia prata, herbe, pasthua et aque ad usus sui bestiarii et ganati per omnes montes et omnia loca, terre seu dominacionis nostre, libere et quiete, exceptis deffesiis antiquis de Signa et de Redorta, de Pina, que quidem deffesie per antecessores nostros ad sui et suorum usibus retineri noscuntur, ut in dictis privilegiis lacius continetur.» AMZ, Serie diplomática, R-035 (1300, noviembre, 6. Valencia). Regestado en GONZÁLEZ ANTÓN, L., Las uniones aragonesas y las Cortes de reino (1283-1301), CSIC-Escuela de Estudios Medievales, Zaragoza, 1975, vol. II, doc. 434, p. 537.

11 AMZ, Serie diplomática, R-036, R-037, R-038, R-039, R-039bis P-046 y P-047. Éste último documento fue publicado por CANELLAS LÓPEZ, A., Diplomatario medieval de la Casa de Ganaderos de Zaragoza, Real Sociedad Economica Aragonesa de Amigos del País, Zaragoza, 1988, doc. 30, pp. 81-82.

12 «Cum intellexerimus, pro parte iuratorum et universitatis civitatis Cesarauguste, quod licet ganaderii sive habentes bestiaria in dicta civitate Cesarauguste consueverint, a tanto tempore citra quod memoria hominum in contrarium non existit, pastare et adaquare eorum bestiaria in terminis de Albarrazino, solvendo pro qualibet cabanna ganati quinque arietes sive carneros (...).» AMZ, Serie diplomática, R-063 (1326, septiembre, 7. Barcelona). 
vecinos de la capital, con la salvedad de que, en este caso, las excepciones contempladas iban a desempeñar un papel mucho más relevante ${ }^{13}$. Se trataba, en primer lugar, de los puestos de Teruel y Albarracín, situados en la densa vía de comunicación con la ciudad de Valencia, y, sobre todo, del puesto de Tortosa, un lugar especialmente rentable para el cobro de estos tributos debido a que era allí, precisamente, donde iba a parar la mayor parte de los productos con los que comerciaban los mercaderes e inversores zaragozanos $^{14}$. Entre estos productos, destacan el trigo y la lana que, sobre la vía fluvial del Ebro, viajaban hasta el puerto de Tortosa para embarcar rumbo a los mercados de Barcelona o Valencia ${ }^{15}$. Como veremos algo más adelante, el peaje de Tortosa suponía, a comienzos del siglo XIV, una carga importante para la oligarquía zaragozana y hemos de suponer, también, que permitía al rey mantener el precio de su arrendamiento en una cantidad elevada, obteniendo así pingües beneficios.

Pero, al igual que acabamos de ver para el caso de los derechos de pasto, también el cobro de lezdas y peajes a mercaderes zaragozanos constituía una tentación difícil de eludir para los oficiales correspondientes, de manera que, con cierta frecuencia, se producían excesos en este sentido, que exigían de la

13 AMZ, Serie diplomática, R-040 (1300, noviembre, 16. Valencia).

14 Sobre el tránsito de mercancías entre Aragón y Valencia, véase SESMA MUÑOZ, J.A. «Adaptación socio-espacial de las comunidades mudéjares dedicadas al transporte entre Aragón y Valencia (siglos XIV-XV)», La pervivencia del concepto. Nuevas reflexiones sobre la ordenación social del espacio en la Edad Media, eds. J.A. Sesma Muñoz y C. Laliena Corbera, Zaragoza, 2008, pp. 409-426; VILLANUEVA MORTE, Concepción, «Las relaciones económicas entre los reinos de Aragón y Valencia en la Baja Edad Media», La Mediterrània de la Corona d'Aragó, segles XIII-XVI VII centenari de la Sentència arbitral de Torrellas, 1304-2004, XVIII Congreso de Historia de la Corona de Aragón, Valencia, 2005, v. 1, pp. 1321-1350; y RUBIO VELA, A. «Trigo de Aragón en la Valencia del Trescientos», en J.A. Sesma Muñoz y C. Laliena Corbera (coords.), Crecimiento económico y formación de los mercados en Aragón en la Edad Media (1200-1350), Grupo CEMA-Gobierno de Aragón, Zaragoza, 2009, pp. 319-368. Para la exportación de mercancías desde Aragón a través de Tortosa, SESMA MUÑOZ, José Ángel, «Centros de producción y redes de distribución en los espacios interiores de la Corona de Aragón: materias primas y productos básicos», La Mediterrània de la Corona d'Aragó, segles XIII-XVI \& VII Centenari de la Sentència Arbitral de Torrellas, 1304-2004, XVIII Congrés d'Història de la Corona d'Aragó, Valencia, 2005, pp. 903-938; y «El comercio exterior de la Corona por vías terrestres. Un comercio intenso y fragmentado», $L a$ Corona de Aragón en el centro de su Historia. 1208-1458. Aspectos económicos y sociales, coord. J.A. Sesma Muñoz, Grupo CEMA-Gobierno de Aragón, Zaragoza, 2010, pp. 345-362.

15 LOZANO GRACIA, S. y M. ${ }^{a}$ T. SAUCO ÁlVAREZ, «El puerto de Tortosa: lugar de convergencia de mercaderes mediterráneos según los protocolos notariales tortosinos (siglo XV)», La Mediterrània de la Corona d'Aragó, segles XIII-XVI VII centenari de la Sentència arbitral de Torrellas, 1304-2004, XVIII Congreso de Historia de la Corona de Aragón, Valencia, 2005, v. 2, pp. 1249-1268. 
intervención real y que podían dar lugar a soluciones diversas. Los ejemplos en este campo son también numerosos, pero interesa destacar especialmente dos de ellos: en mayo de 1336, a los pocos meses de comenzar su reinado, Pedro IV fue requerido por el concejo de Zaragoza para que confirmase expresamente la exención del pago de estos derechos en la ciudad de Lérida, lo cual nos indica que, muy probablemente, los peajeros de esta ciudad tenían una percepción bastante subjetiva sobre la inmunidad de los zaragozanos ${ }^{16}$. Y este mismo fenómeno se constata también dentro del propio reino, ya que un año más tarde el citado monarca hubo de confirmar, también de modo particular, la exención disfrutada sobre el peaje de Calatayud, aludiendo, a su vez, a un privilegio emitido por su padre, Alfonso IV y, por lo tanto, no anterior a $1327^{17}$.

Mantener la vigencia del privilegio era, por lo tanto, una cuestión de autoridad y, también, de fuerza, dado que el cumplimiento de las leyes -no hará falta insistir en ello- suele requerir, históricamente, de la activa participación de los agentes sociales. Como hemos visto hasta ahora, la acción de la oligarquía zaragozana en este terreno fue lo suficientemente eficaz como para hacer valer, prácticamente siempre que tuvo ocasión, la operatividad de unos privilegios no siempre claros en su forma ni mucho menos en su alcance, conservando así una inmunidad tributaria muy extensa. Esta acción fue secular y, en cierto sentido, cotidiana, dado que las diferencias en la interpretación de los privilegios, en Zaragoza como en todas partes, se producían con una elevada frecuencia. Pero, junto a estas oportunidades, existieron además otros contextos menos cotidianos en los que la corporación municipal pudo negociar con la monarquía no sólo para la conservación de sus privilegios, sino, sobre todo, para su ampliación. Se trata, como anticipamos en la introducción, de los procesos de negociación desarrollados a instancia de la monarquía, con el fin de obtener servicios económicos extraordinarios.

\section{OPORTUNIDADES PARA LA AMPLIACIÓN DE LOS PRIVILEGIOS}

Desde finales del siglo XIII y durante toda la primera mitad del XIV, el procedimiento empleado con mayor frecuencia por la monarquía aragonesa para la obteción de servicios económicos extraordinarios fue la negociación con los poderes municipales de realengo y los titulares de señoríos eclesiásticos, bien de modo particular o bien mediante la convocatoria de parlamentos a los que debían concurrir representantes de distintas villas y ciudades. Con la

16 AMZ, Serie diplomática, R-074 (1336, mayo, 23. Zaragoza).

17 AMZ, Serie diplomática, R-047 y R-077 (1337, julio, 19. Gandesa). 
creación de las diputaciones territoriales en los tres Estados cismarinos de la Corona, a partir de la década de 1350 , los grandes servicios -y, por lo tanto, las negociaciones decisivas- se concentraron en las Cortes, tanto privativas (a nivel de cada uno de los territorios) como generales (donde concurrían representantes de todos los órdenes y de los tres estados peninsulares de la Corona, junto con Mallorca) ${ }^{18}$. La relevancia adquirida por la actividad parlamentaria a la hora de resolver las demandas económicas de la monarquía y, de manera prácticamente simultánea, los problemas económicos de las respectivas Diputaciones, no fue incompatible, sin embargo, con el hecho de que los distintos monarcas continuaran recurriendo, más allá de 1350, a determinados concejos para solicitar donativos y negociar, por lo tanto, las correspondientes contraprestaciones ${ }^{19}$. Por lo que sabemos hasta ahora, al menos en Aragón, con posterioridad a la última fecha citada estas demandas solían concretarse en forma de ayudas menores, pero cuyas condiciones podían ser, claro está, decisivas desde el punto de vista de la Historia local.

Dentro de la secuencia que acabamos de enunciar, la fase inicial, es decir, el medio siglo largo transcurrido entre comienzo del reinado de Jaime II (en 1291) y el inicio del predominio de las Cortes a mediados del Trescientos, constituyó uno de los periodos en que se desarrollaron de modo más intenso las negociaciones directas entre la monarquía y el concejo de Zaragoza. La resolución de este tipo de negociaciones llevaba necesariamente aparejado el reconocimiento, por parte del rey, de la inmutabilidad de los estatutos y privilegios de la entidad otorgante como consecuencia del donativo concedido, un requisito firmemente encuadrado entre las fórmulas recogidas en los documentos y cuyo significado es suficientemente conocido. Así, cuando la cuantía del donativo era menor -0 , al menos, era considerada como tal por sus negociadores-, el monarca únicamente ofrecía a cambio su compromiso de no utilizar, en el futuro, dicha concesión como un precedente para futuras exigencias económicas ni de cualquier otro tipo. Un ejemplo relativamente temprano de este tipo de acuerdo nos lo proporciona la ratificación de los

18 SÁNCHEZ MARTÍNEZ, M., A. FURIÓ DIEGO y J.A. SESMA MUÑOZ, «Old and New Forms of Taxation in the Crown of Aragon (13th-14th Centuries)», La fiscalità nell'economia europea (sec. XIII-XVIII), XXXIX Settimana di Studi dell'Istituto Internazional di Storia Economica «Francesco Datini» di Prato, coord. S. Cavachiocci, Prato, 2008, pp. 99-130; SESMA MUÑOZ, J.A., «Las transformaciones de la fiscalidad real en la baja Edad Media», El poder real en la Corona de Aragón (siglos XIV-XVI), XV Congreso de Historia de la Corona de Aragón, Zaragoza, 1997, t. I, v. 1, pp. 231-292

19 SÁNCHEZ MARTÍNEZ, M., «La monarquía y las ciudades desde el observatorio de la fiscalidad», La Corona de Aragón en el centro de su Historia. 1208-1458. La monarquía aragonesa y los reinos de la Corona, coord. J.A. Sesma Muñoz, Grupo CEMA-Universidad de Zaragoza, Zaragoza, 2009, pp. 45-66. 
privilegios de Zaragoza realizada por Jaime II en diciembre de 1312, después de recibir un donativo de 20.000 sueldos jaqueses de la ciudad, con motivo de los matrimonios de las infantas María y Constanza ${ }^{20}$.

Otros servicios, sin embargo, alcanzaron una mayor magnitud y, entre ellos, merece la pena destacar el que tuvo lugar en el bienio 1319-1320, el cual significó, para los zaragozanos, la exención perpetua del pago de lezdas y peajes en Tortosa, un tributo que, como anticipábamos hace algunos minutos, venía suponiendo verdaderos quebraderos de cabeza al sector dirigente de la ciudad. A cambio, los representantes del concejo hubieron de comprometerse a entregar al monarca la importante cantidad de 50.000 sueldos jaqueses, un precio elevado, sin duda, pero equiparable al nivel del privilegio obtenido $^{21}$. La inmunidad sobre el peaje de Tortosa vino acompañada, asimismo, de una medida altamente representativa de los intereses y estrategias presentes en el seno de la elite zaragozana. Se trata de la aplicación, por parte del consistorio, de una tasa (tres dineros por libra) sobre las mercancías que salieran desde Zaragoza hacia Tortosa, con el fin de recaudar 12.000 de los 50.000 sueldos jaqueses otorgados. Esta solución fue completada, a su vez, mediante el arrendamiento del impuesto, que recayó en manos de seis vecinos de la ciudad: Juan de Ahuero, Juan Pérez Vigores, Domingo Pérez de Tauste, Juan de Ejea, Pedro López Sarnés y Tomás de Pina ${ }^{22}$.

20 AMZ, Serie diplomática, R-052 (1312, diciembre, 19. Calatayud). La infanta María casó con el infante Pedro, hermano de Fernando IV de Castilla, mientras que Constanza lo hizo con el infante castellano don Juan Manuel. Ambos matrimonios se habían concertado en una entrevista celebrada en Calatayud, entre finales de 1311 y comienzos de 1312, y, de hecho, el primero de ellos se llevó a efecto en esta misma villa, en la iglesia de Santa María, a finales del mes de enero de 1312. Todos estos contratos forman parte del proceso de negociación política que siguió a la firma de la paz de Torrellas (1304) y al tratado de Elche (1305). LAFUENTE GÓMEZ, M., «Encrucijadas dinásticas: conflictos nobiliarios e intervenciones aragonesas en la Corona de Castilla (1276-1312)», Cuadernos del CEHIMO, 39 (2013), pp. 7-38, concretamente pp. 33-34.

21 AMZ, Serie diplomática, P-066 (1319, diciembre, 10. Zaragoza); y AMZ, Serie diplomática, R-053 (1320, marzo, 4. Tarragona).

22 «[El concejo de la ciudad] damos e femos cession, e por raçon e titol de vendicion livramos a vos, don Johan de Avuero, Johan Pereç Vigoros, el joven, don Domingo Perez de Thaust, don Johan de Exea, don Pero Lopeç Sarnes, Tomas de Pina, veçinos de la dita ciudat, e a los vuestros e a qui vos querredes, dotze milia solidos jaqueses, los quales los mercaderos e qualesquiere otros veçinos de la dita ciudat qui levaran pan e qualesquiere otras mercaderias a la ciudat de Tortosa, deven e son tenidos dar a la dita ciudat, es a saber tres dineros por livra, en ayuda de aquellos cinquanta mil solidos barcaloneses, los quales la dita ciudat dio e pago al sennyor rey por la conposicion feyta entre el dito sennyor rey e la dita ciudat, por racon de la lezda que el sennyor rey dizia a los homes de la dita ciudat de Caragoça dever pagar en Tortosa.» AMZ, Serie diplomática, P-070 (1320, agosto, 15. Zaragoza). 
Por el momento en que se produjo el donativo, cabría relacionarlo con las demandas efectuadas por Jaime II para dotar materialmente la armada destinada a la conquista de Cerdeña, bajo la dirección del infante Alfonso, aunque no disponemos, hasta el momento, de ninguna referencia directa que confirme dicha relación. Sí consta, sin embargo, una contribución de 20.000 sueldos jaqueses realizada por la ciudad con motivo de la campaña sarda, en $1321^{23}$, y una nueva exención del cobro de derechos de tránsito dada a comienzos de ese mismo año, esta vez sobre la localidad aragonesa de Albalate de Cinca y emitida, precisamente, por el propio infante Alfonso ${ }^{24}$.

Las cinco primeras décadas del siglo XIV presentan también una particularidad interesante en lo que respecta a la resolución de las negociaciones desarrolladas entre la monarquía y la ciudad de Zaragoza, en torno a la consecución de servicios económicos extraordinarios, por parte de la primera, y de nuevos y mayores privilegios, por la segunda. Se trata del hábito, documentado hasta en tres ocasiones, de resolver el donativo atribuido a la ciudad en especie, en lugar de hacerlo en moneda. Concretamente, el concejo de Zaragoza se comprometió a pagar al rey en cereal durante los ciclos fiscales ejecutados con motivo de la campaña dirigida contra Almería (1309), de la reintegración del reino de Mallorca a la Corona de Aragón (1342-1344) y de la gran armada organizada para sofocar la rebelión sarda (1354-1355). No se ha podido documentar, hasta el momento, la cantidad global de la ayuda concedida por la ciudad en el primero de de estos tres casos, pero sí en los dos siguientes, en los que la ciudad otorgó 3.000 y 4.000 cahíces de trigo, es decir, 450 y 600 toneladas, respectivamente ${ }^{25}$. Si tenemos en cuenta el

23 SÁNCHEZ MARTíNEZ, M., «Contributi finanziari di città e ville della Catalogna alla conquista del regno di Sardegna e Corsica (1321-1326)», Medioevo. Saggi e Rassegne, 20 (1995), pp. 317-352 (donde se incluye, también, un desglose general de las aportaciones de los reinos de Aragón, Valencia, Mallorca y Sicilia). Sobre la contribución del realengo aragonés, véase LAFUENTE GÓMEZ, M., «La incidencia de la fiscalidad real extraordinaria sobre las villas y comunidades de la Extremadura aragonesa: Calatayud, Daroca y Teruel (1309-1365)», La historia peninsular en los espacios de frontera: las Extremaduras Históricas y la Transierra (siglos XI-XV), coord. F. García Fitz y J.F. Jiménez Alcázar, Sociedad Española de Estudios Medievales, CáceresMurcia, 2012, pp. 153-177, concretamente pp. 159-162.

24 AMZ, Serie diplomática, R-057 (1321, enero, 21. Zaragoza).

25 Para 1309, únicamente contamos con una referencia indirecta: la solicitud que los jurados de Zaragoza dirigieron al concejo de Longares, aldea de la ciudad, reclamándole la entrega de 128 cahíces de ordio para completar el donativo ofrecido al rey. La solicitud, sin embargo, topó con la resistencia de las autoridades de la aldea y, tras un breve litigio, fue retirada. CANELLAS LÓPEZ, A., Longares, de los orígenes a 1478. Notas históricas y colección diplomática, Zaragoza, 1983, doc. 3 (1310, febrero, 26. Zaragoza). El despliegue económico vinculado a esta campaña en el conjunto de la Corona ha sido analizado minuciosamente por Vicent Baydal, sin que este autor haya 
perfil comercial del grupo dominante de la oligarquía zaragozana en estos momentos y, asimismo, el peso específico del sector cerealista entre sus intereses de mercado, cabría pensar que la adopción de este particular sistema de contribución en las armadas de la monarquía fue diseñado para ofrecer oportunidades de negocio a los grandes mercaderes de la ciudad. No obstante, este aspecto ha de quedar, por el momento, en el aire.

Con el paso del tiempo, la hegemonía de las Cortes y la Diputación a la hora de fiscalizar las grandes demandas de la monarquía no impidió, tal y como apuntábamos hace un momento, que los sucesivos monarcas recurrieran puntualmente al concejo de Zaragoza para solicitar distintas ayudas y que, por lo tanto, los oficiales de la ciudad continuaran jugando sus bazas con el objetivo de progresar en su condición privilegiada. Dos casos, relativamente tardíos, dan buena cuenta de este fenómeno: el primero de ellos corresponde a la ampliación de la exención del pago del impuesto del monedaje o maravedí al conjunto de los vecinos de la ciudad, otorgada por Alfonso $\mathrm{V}$ en 1431, a cambio del pago de 10.000 florines de oro (aproximadamente 100.000 sueldos jaqueses) ${ }^{26}$. El segundo, datado en 1453, significó la con-

podido documentar tampoco el monto total de la aportación zaragozana. Es probable, sin embargo, que una parte del cereal panificable que pasó por la ciudad (el necesario para la elaboración de $178.836 \mathrm{~kg}$ de bizcocho) o del grano destinado a la alimentación de las monturas (5.000 cahíces, equivalentes a $750.000 \mathrm{~kg}$ ) hubiera sido aportado directamente por el concejo en forma de donativo. BAYDAL SALA, V., «Tan grans messions. La financiación de la cruzada de Jaime II de Aragón contra Almería en 1309», Medievalismo, 19 (2009), pp. 57-154, concretamente pp. 68-70. Para 1342-1344, véase AMZ, Serie diplomática, R-101 (1344, abril, 21. Barcelona). Es probable, no obtstante, que ese donativo de 3.000 cahíces de trigo documentado en 1344 represente tan sólo una parte de la aportación de la ciudad. Por último, los datos relativos a 1354-1355 están recogidos en LAFUENTE GÓMEZ, M., Guerra en ultramar. La intervención aragonesa en el dominio de Cerdeña (1354-1355), Institución Fernando el Católico, Zaragoza, 2011, pp. 73-78. La equivalencia métrica que aplicamos atribuye al cahíz aragonés $150 \mathrm{~kg}$ y se basa en las consideraciones de LARA IZQUIERDO, P., Sistema aragonés de pesos y medidas. La metrología histórica aragonesa y sus relaciones con la castellana, Guara, Zaragoza, 1984, pp. 77, 127, 147 y 159; y SESMA MUÑOZ, J.A., «Del Cantábrico al Mediterráneo: la vía fluvial del Ebro», Itinerarios medievales e identidad hispánica, XXVII Semana de Estudios Medievales de Estella, Gobierno De Navarra, Pamplona, 2001, pp. 189-220. Asimismo, conviene señalar que el peso del cahíz valenciano a mediados del siglo XIV ha sido estimado en 150,75 kg. SÁNCHEZ MARTíNEZ, M., «Guerra, avituallamiento del ejército y carestías en la Corona de Aragón: la provisión de cereal para la expedición granadina de Alfonso el Benigno (1329-1333)», Historia. Instituciones. Documentos, 20 (1993), pp. 523-549, concretamente p. 527.

26 Publicado por FALCÓN PÉREZ, M. ${ }^{a}$ I., Ordinaciones reales otorgadas a la ciudad de Zaragoza en el siglo XV: de Fernando I a Fernando II, Institución Fernando el Católico, Zaragoza, 2010, doc. XXI (1431, marzo, 17. Lérida), pp. 163-171. Conviene advertir que la elite de los ciudadanos honrados ya disfrutaban de la exención de este impuesto real desde 1348, como se verá en el apartado siguiente. 
cesión por parte del citado monarca del sistema de la insaculación para la designación del juez de la ciudad, en lugar del nombramiento real existente hasta entonces, a cambio, en esta ocasión, del pago de 1.000 florines (unos 10.000 sueldos) $)^{27}$.

\section{CONFIGURACIÓN DE UN ESTATUS DE SUPERIORIDAD SOCIAL PROPIO DE LA OLIGARQUÍA URBANA: LOS CIUDADANOS HONRA- DOS}

Hasta aquí, hemos tratado de explicar cómo la condición privilegiada de la ciudad de Zaragoza y de sus habitantes, con respecto al resto de las villas y ciudades del reino de Aragón, fue definiéndose a lo largo de un proceso que comenzó inmediatamente después de la conquista feudal y en el que participaron activamente tanto la monarquía como la oligarquía urbana. Ambas partes incluyeron, entre sus estrategias de consolidación y promoción política, la conservación de la identidad eminente propia de la antigua civitas romana, si bien lo hicieron por diferentes motivos: para la monarquía, significaba una inyección constante de legitimidad y un medio de hacer visible el poder de la dinastía; para los vecinos que ejercían el poder local, era una forma de avanzar hacia la inmunidad plena o, lo que es lo mismo, hacia un estado de libertad propio de la aristocracia de sangre ${ }^{28}$.

No cabe duda, y así lo hemos constatado, que dicha identidad se construyó en torno al mantenimiento y a la ampliación de la exención fiscal en beneficio de los habitantes de la ciudad, pero además conviene añadir otro aspecto no menos significativo, como es la configuración de un estatus de superioridad propio de la oligarquía urbana, cuya raíz se encuentra precisamente en el contexto de la conquista y que había supuesto, en aquel momento, la extensión de la infanzonía a los pobladores de la capital.

La equiparación estatutaria entre los habitantes de Zaragoza y los infanzones de Aragón se había concretado entonces, como hemos visto, mediante la entrega y aplicación del Fuero de los infanzones de Aragón a la ciudad, en 1119. El contenido de este código estaba orientado a definir, fundamentalmente, el tipo de prestación militar que, en adelante, deberían ofrecer los

27 FALCÓN PÉREZ, M. ${ }^{a}$ I., Ordinaciones reales, cit., doc. XXXVI, pp. 226-229 (Castro de Silva Voyra. 1453, septiembre, 9).

28 Sobre la función de la ciudad como elemento de proyección del poder real, en el caso de Zaragoza, véase el trabajo de BARRAQUÉ, J.P., «Entre religión real y religión urbana», En la España Medieval, 31 (2008), pp. 249-274. Para Valencia, NARBONA VIZCAÍNO, R., «La fiesta cívica, rito del poder real: Valencia, siglos XIV-XVI», El poder real en la Corona de Aragón (siglos XIV-XVI), XV Congreso de Historia de la Corona de Aragón, Zaragoza, 1996, v. 3, pp. 401-420. 
zaragozanos al rey, y empleaba, para ello, las fórmulas propias del contrato feudal que vinculaba a la monarquía con el sector más eminenete de la aristocracia del reino (barones y grandes milites). Este sistema estaba organizado en torno a dos pautas distintas que, a su vez, encuadraba a sus beneficiarios en dos grupos diferenciados: de un lado, se encontraban aquellos sujetos que no disfrutaban de honor, esto es, de algún tipo de feudo o beneficio otorgado por un superior, cuya prestación quedaba restringida a los casos de asedio y batalla campal, siempre al servicio del rey, asumiendo el coste de su propio servicio únicamente durante tres días ${ }^{29}$. La segunda prescripción concernía a los titulares de honores y los obligaba a combatir únicamente para la defensa de su honor, es decir, de su feudo ${ }^{30}$. Ambas disposiciones transcribían unas pautas de relación basadas en el auxilium militar y, por lo tanto, difícilmente asumibles por la población urbana, de modo que que, con el tiempo, el estatus de superioridad de la elite zaragozana hubo de formularse en términos sensiblemente distintos. La ocasión para plasmar por escrito esta distinguida condición social se produjo en el contexto de la Segunda Unión, un conflicto nobiliario y urbano que, si bien concluyó con la victoria del bando realista, significó la entrada en vigor de algunas leyes dirigidas a equilibrar la relación de poder entre el monarca y los sectores más reaccionarios de la sociedad política ${ }^{31}$.

En este contexto, y en el marco de las Cortes celebradas en Zaragoza en 1348, inmediatamente después de darse por cerrado el conflicto, Pedro IV

29 «Et habent fueros infantiones de Aragone qui non tenent honore de seniore: quod vadat ad lite campale et a sitio de castellum cum pane de tres dies; et nullus infantione qui ibi non quiesierit ire, non habeat super illum nullam caloniam nisi quod vetet rex de terra suos mercatos, quod non ibi comparet nec vendat; et suos alcaldes quod non illum iudicent.» CANELLAS, A., Colección Diplomática, cit., t. I, p. 83.

30 «Et illos infantiones qui habuerunt et tenuerunt honores de seniore, si fuerit reptato, non faciat directum, nisi in illa honore stando.» Ibídem, p. 83.

31 Para el desarrollo del conflicto unionista a mediados del siglo XIV, véase SARASA SÁNCHEZ, E., «El enfrentamiento de Pedro el Ceremonioso con la aristocracia aragonesa», en Pere el Cerimoniós i la seva època, Barcelona, CSIC-Institució Milá i Fontanals, 1989, pp. 35-38; SESMA MUÑOZ, J.A., «El poder real», en Ceremonial de la consagración y coronación de los reyes de Aragón. Ms. R. 14.425 de la Biblioteca de la Fundación Lázaro Galdiano, Centro de Documentación Bibliográfica Aragonesa, Zaragoza, 1991-1992, v. 2, pp. 99-100; y SIMÓN BALLESTEROS, S., «El acuerdo secreto firmado entre el rey Pedro IV y el noble aragonés Lope de Luna durante la segunda Unión (1347-1348)», Aragón en la Edad Media, XXII (2011), pp. 247-269. Asimismo, puede consultarse la edición de los documentos generados por las Cortes del reino entre 1347 y 1349, asambleas dedicadas casi exclusivamente a los problemas de la Unión. SESMA MUÑOZ, J.A. y M. LAFUENTE GÓMEZ (eds.), Cortes de Pedro IV/1, Acta Curiarum regni Aragonum, t. II, Grupo CEMA, Gobierno de Aragón, Cortes de Aragón e Ibercaja, Zaragoza, 2013, pp. XVII-XXIV y 21-143. 
otorgó a la ciudad un privilegio mediante el cual se definía con precisión el estatus de los ciudadanos honrados y los beneficios asociados al mismo ${ }^{32}$. Según este texto, la adscripción a la ciudadanía quedaba restringida a los varones que, además de ser vecinos de la ciudad, mantuviesen una montura y un arnés de combate de modo permanente, y, además, no desempeñaran oficios "manuales", un rasgo de distinción típicamente nobiliario ${ }^{33}$. Los tres requisitos remiten a un proceso de aristocratización de las elites urbanas constatado a nivel europeo y, especialmente, en las grandes ciudades de todo el arco mediterráneo, incluida la Corona de Aragón ${ }^{34}$. Pero, además de definir formalmente este nuevo estatus jurídico, el privilegio establecía también el modo en que se debía concretar, en adelante, la identificación formal de este selecto grupo social. Concretamente, eran otros tres los elementos distintivos: la exención del pago del monedaje al rey, la liberación de cargas para todas las propiedades adquiridas en el reino por los ciudadanos y la posibilidad de ser investidos caballeros sin mediación real.

Merece la pena detenerse en esta última prerrogativa, según la cual, los varones más poderosos de la ciudad pasaban a disfrutar, en apariencia, de plena libertad para recibir la investidura en armas y asumir, así, ese estatus de superioridad social que significaba la caballería. Los análisis elaborados hasta ahora sobre este aspecto, sin embargo, apuntan a que fueron pocos los ciudadanos honrados que, realmente, accedieron a dar este paso. Sobre una muestra prácticamente completa de las familias e individuos que ostentaban la ciudadanía en Zaragoza entre 1420 y 1475, la Dra. Susana Lozano ha documentado tan solo catorce casos de investidura en armas como consecuencia directa de la aplicación del privilegio de $1348^{35}$. Según la citada autora, todos

32 AMZ, Serie diplomática, R-107 (1348, septiembre, 24. Zaragoza).

33 MAINÉ BURGUETE, E., Ciudadanos honrados de Zaragoza. La oligarquía zaragozana en la baja Edad Media (1370-1410), Grupo CEMA-Universidad de Zaragoza, Zaragoza, 2006.

34 MAIRE VIGUEUR, J. M., Cavaliers et citoyens. Guerre, conflits et société dans l'Italie communale, XII-XIII siècles, École des Hautes Études en Sciences Sociales, Paris, 2003; CASTELNUOVO, G., «Vivre dans l'ambiguité: être noble dans la cité communale du XIV ${ }^{\text {e }}$ iècle», Famiglie e poteri in Italia tra Medioevo ed Età Moderna, a cura di A. Bellavitis e I. Chabot, École Française de Rome, Roma, 2009, pp. 95-116; LALIENA CORBERA, C., «Las transformaciones de las elites políticas de las ciudades mediterráneas hacia 1300: cambios internos y movilidad social», La mobilità sociale nel Medioevo, ed. S. Carocci, École Française de Rome, Roma, 2010, pp. 147-185.

35 Además, otros dos individuos fueron investidos como caballeros directamente por el monarca, sin mediar la aplicación del privilegio. LOZANO GRACIA, S., Las elites en la ciudad de Zaragoza a mediados del siglo XV: la aplicación del método prosopográfico en el estudio de la sociedad, Tesis doctoral, Universidad de Zaragoza, 2008, pp. 766-769 (disponible en red: http://zaguan.unizar.es/record/7400?ln=es). 
estos casos apuntan además a una finalidad estrictamente simbólica, dado que los sujetos que recibieron la orden de caballería desde la condición de ciudadanos lo hicieron a una edad avanzada y una vez que hubieron cedido la titularidad de sus negocios (fundamentalmente notarías, responsabilidades de tipo comercial o talleres de alta cualificación) a sus herederos ${ }^{36}$.

Pero, sin duda, la gran baza de la ciudadanía se situó durante toda la Baja Edad Media en el monopolio del ejercicio del poder local, dado que aquella constituía un requisito innegociable para acceder al desempeño de los cargos propios del concejo. En este sentido, conviene destacar que el poder municipal en la capital aragonesa estuvo desde, al menos, finales del siglo XIII, en manos de aquellos vecinos más poderosos de la ciudad que, bajo la consideración prácticamente universal de hombres buenos o probi homines, se impusieron secularmente a la aristocracia de sangre. Desde 1348 y a raíz del privilegio citado anteriormente, fue la categoría de ciudadano honrado la que sirvió para definir el espectro social donde reclutar a los oficiales más importantes del concejo (el juez o zalmedina y los jurados) y, en adelante, los miembros de esta oligarquía sostuvieron una estrategia extraordinariamente agresiva para mantener a infanzones y caballeros fuera del consistorio. De hecho, este objetivo figuró siempre entre los intereses más y mejor defendidos por los representantes de la ciudad ante el poder real ${ }^{37}$.

Las ocasiones para ello fueron relativamente frecuentes durante toda la Baja Edad Media y, muy especialmente, en el siglo XV, cuando, a pesar de las numerosas revisiones efectuadas sobre el procedimiento de elección de los oficios, y a pesar incluso de su supeditación al intervencionismo regio durante el reinado de Fernando II, la discriminación de la nobleza permaneció en todo momento como una condición inalterable. Es preciso señalar, en este sentido, las actuaciones de la reina María en 1421, al disponer que el Justicia y el gobernador del reino se encargaran de asegurar la no intro-

36 Ibídem, pp. 771-774.

37 La trayectoria de Zaragoza, en lo que respecta a la configuración de las estructuras del poder local, es comparable a la experimentada en las otras dos grandes ciudades de la Corona de Aragón cismarina, es decir, Barcelona y Valencia, aunque faltan todavía estudios de Historia comparada que sincronicen problemáticas y unifiquen cuestionarios. Véanse, respectivamente, los trabajos de ORTí GOST, Pere, «El Consell de Cent durant l'Edat Mitjana», Barcelona, quaderns d'història, 4 (2001), pp. 2148, especialmente pp. 43-48; y NARBONA VIZCAÍNO, R., «Cultura política y comunidad urbana: Valencia, siglos XIV-XV», Edad Media: revista de historia, 14 (2013), pp. 171-211, especialmente pp. 177-182. También, desde un punto de vista general, el trabajo de NARBONA VIZCAÍNO, R., «Algunas reflexiones sobre la participación vecinal en el gobierno de las ciudades de la Corona de Aragón (ss. XIIXV)», Res publica: revista de filosofía política, 17 (2007), pp. 113-150. 
misión de infanzones en el proceso de elección de los cargos y oficios de la ciudad ${ }^{38}$, y en 1442, cuando emitió unas disposiciones sobre la insaculación de los candidatos a integrar el concejo ${ }^{39}$. Asimismo, en las reformas introducidas por Alfonso V, en $1430^{40}$, y, sobre todo, al reconocer el concejo la potestad del nombramiento de los cargos municipales a Fernando II, en 1487 y 1506, quedó explícita la estricta separación de cualquier candidatura procedente de la pequeña nobleza ${ }^{41}$.

\section{CONCLUSIÓN}

En este trabajo hemos intentado mostrar cómo la conservación del estatus privilegiado propio de la ciudad de Zaragoza se inscribió, en la Baja Edad Media, dentro de una dinámica de construcción del derecho basada en la negociación y el pacto, cuyos rasgos principales se manifestaron también en otras grandes ciudades de la Corona de Aragón, especialmente Barcelona y Valencia. Como hemos venido argumentando hasta aquí, el perfeccionamiento progresivo de los estatutos otorgados por Alfonso I en las primeras décadas del siglo XII, fue el resultado de la interacción secular de dos factores complementarios: de un lado, el papel de la monarquía como fuente de legitimidad y como agente interesado en mantener la eminencia de la ciudad, y, de otro, la permanente labor de las autoridades locales para defender su distinción a lo largo del tiempo. La concurrencia de ambos factores dio lugar a una densa secuencia de conflictos, negociaciones y encuentros de todo tipo, cuyo denominador común fue la necesidad de definir, periódicamente, el sentido práctico de los privilegios reconocidos a la ciudad.

La participación de la oligarquía local en este proceso, lejos de venir motivada por intereses aislados o meramente coyunturales, permite detectar estrategias de reproducción y promoción social a medio y largo plazo, apoyadas tanto en el ámbito de lo material (fortunas familiares vinculadas a la ganadería y el comercio) como en el de lo simbólico (el prestigio asociado a las categorías de infanzonía y ciudadanía). Los tres aspectos analizados aquí han pretendido cubrir una parte significativa de esos dos espacios, al observar los problemas relacionados con la aplicación de las exenciones vinculadas a los derechos de pasto y de tránsito, el modo en que las autoridades locales aprovecharon las oportunidades para la ampliación de la inmunidad

38 FALCÓN PÉREZ, M. ${ }^{a}$ I., Ordinaciones reales, cit., doc. XIV (1421, noviembre, 19. Barcelona), pp. 128-129.

39 Ibídem, doc. XXVII (1442, febrero, 26. Zaragoza), pp. 185-204.

40 Ibídem, doc. XIX (1430, mayo, 29. Cariñena), pp. 157-159.

${ }^{41}$ Ibídem, doc. XLIX (1487, noviembre, 10 y 11), pp. 261-268 y 277-284 respectivamente. 
fiscal y el empeño del grupo urbano dominante por obtener, al menos en lo formal, la plena identificación con la pequeña nobleza del reino. Existieron, no obstante, otros fenómenos históricos susceptibles de ser incluidos en este planteamiento, entre los que cabría sugerir, por ejemplo, la relación establecida entre la ciudad de Zaragoza y otras entidades del reino (ciudades, señoríos, comunidades) o el grado de representatividad del concejo, como vehículo institucional del conjunto de los vecinos, ante los diversos procesos de negociación. Cuestiones que, esperamos, puedan ser abordadas en un futuro próximo. 